\title{
Thanatosis in a Green Forest Lizard, Calotes calotes (Linnaeus 1758)
}

\author{
Debaprasad Sengupta ${ }^{1}$, Puja Deb ${ }^{2}$, and Prayas Auddy ${ }^{2}$
}

${ }^{1}$ Bansbari Pathar, Dibrugarh-786001, Assam, India (debaprasad.sengupta40@hotmail.com)

${ }^{2}$ Department of Zoology and Wildlife Biology, A.V.C. College (Autonomous), Mannampandal-609305, Tamil Nadu, India

$\mathrm{T}$ hanatosis, also known as death-feigning or a state of tonic immobility, is an anti-predator strategy adopted by diverse prey late in the predation sequence and frequently following physical contact by the predator in order to inhibit further attacks by a predator (Humphreys and Ruxton, 2018). It also can function as an instant response to external stimuli (Muliya et al. 2018). This behavior has been recorded in mammals, birds, fishes, reptiles, amphibians, and arthropods (Vogel and Han-Yuen 2010).

At 2312 h on 8 April 2020, during an ongoing survey of the reptilian fauna at A.V.C. College (Autonomous),

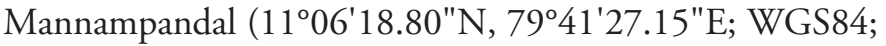
elev. $33 \mathrm{~m}$ asl), we captured a juvenile Green Forest Lizard (Calotes calotes) (SVL $33 \mathrm{~mm}$, tail length $89 \mathrm{~mm}$ ) that we identified based on a description in Daniel (2002). We measured it and, after $168 \mathrm{sec}$, released it on the ground. It immediately turned upside down and remained in that position for $378 \mathrm{sec}$ (Fig. 1) before moving suddenly and climbing a nearby vine.

Animals practicing thanatosis presumably manipulate a predator by sending a false indicator of their death prior to making an escape (Honma et al. 2006). Although thanatosis has been reported for a number of reptilian species (summarized in Patel et al. 2016 and Deshmukh et al. 2020), this behavior is poorly documented in agamid lizards and warrants further study.

\section{Acknowledgements}

We thank the authorities of A.V.C. College (Autonomous) and the Department of Zoology and Wildlife Biology for permitting us to work on campus.

\section{Literature Cited}

Daniel, J.C. 2002. The Book of Indian Reptiles and Amphibians. Oxford University Press, Oxford, UK.

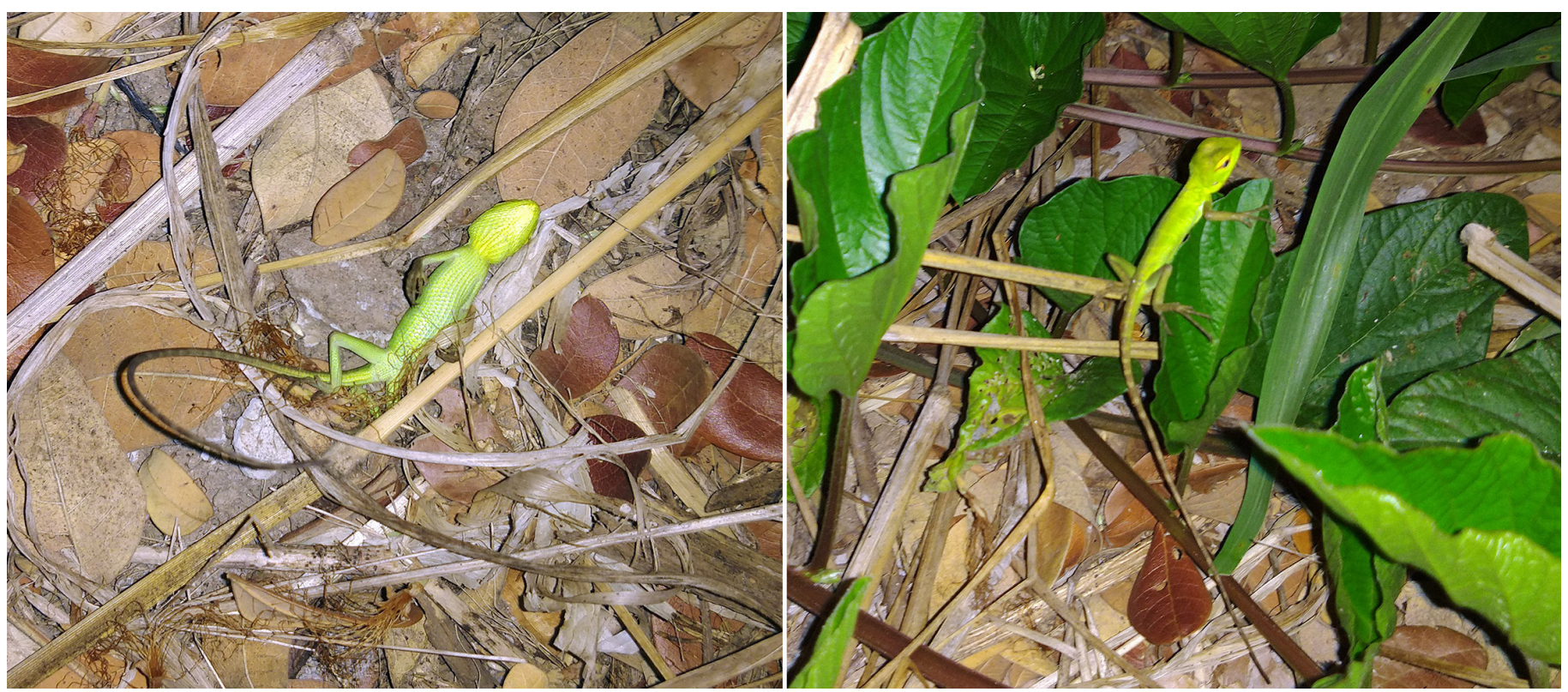

Fig. 1. A juvenile Green Forest Lizard (Calotes calotes) engaged in thanatosis behavior (left) and after recovering from its immobile state and escaping (right). Photographs by Debaprasad Sengupta. 
Deshmukh, R.V., S.A. Deshmukh, S.A. Badhekar, U.M. Udapure, and S.K. Hattimare. 2020. Death-feigning behavior in the Common Sand Boa, Eryx conicus (Schneider 1801) (Erycidae), and the Common Wolfsnake, Lycodon aulicus (Linnaeus 1758) (Colubridae). Reptiles \& Amphibians 27: 65-67.

Honma, A., S. Oku, and T. Nishida. 2006. Adaptive significance of death feigning posture as a specialized inducible defence against gape-limited predators. Proceedings of the Royal Society B: Biological Sciences 273: 1631-1636.

Humphreys, R.K. and G.D. Ruxton. 2018. A review of thanatosis (death feign- ing) as an anti-predator behaviour. Behavioral Ecology and Sociobiology 72: 22 (https://doi.org/10.1007/s00265-017-2436-8).

Muliya, S.K., A. Nath, and A. Das. 2018. First report of death feigning behaviour in the yellow collared wolf snake (Lycodon flavicollis). Herpetological Bulletin 143: 41-42.

Patel, H., V. Naik and S.K. Tank. 2016. Death-feigning behavior in two species of Lygosoma (Squamata, Scincidae) from India. Phyllomedusa 15: 191-194.

Vogel, G. and H.K. Han-Yuem. 2010. Death feigning behavior in three colubrid species of tropical Asia. Russian Journal of Herpetology 17: 15-21. 